BMJ Open Ophthalmology

\section{Benefit of psychiatric evaluation on anxiety in patients with Charles Bonnet syndrome}

To cite: Doeller B,

Kratochwil M, Sifari L, et al. Benefit of psychiatric evaluation on anxiety in patients with Charles Bonnet syndrome. BMJ Open Ophthalmology 2021;6:e000463. doi:10.1136/ bmjophth-2020-000463

Received 24 March 2020 Revised 4 February 2021 Accepted 6 February 2021
Check for updates

(C) Author(s) (or their employer(s)) 2021. Re-use permitted under CC BY-NC. No commercial re-use. See rights and permissions. Published by BMJ

${ }^{1}$ Vienna Institute for Research in Ocular Surgery, Hanusch Hospital, Wien, Austria ${ }^{2}$ Psychiatry and psychotherapy, Hanusch Hospital, Wien, Austria ${ }^{3}$ Ophthalmology, Hanusch Hospital, Wien, Austria

Correspondence to Dr Birgit Doeller; b.doeller@ viros.at

\section{ABSTRACT}

Objective Charles Bonnet syndrome (CBS) is defined as an occurrence of visual hallucinations ( $\mathrm{VHs}$ ) in the absence of any psychiatric/neurological disorder. Significantly reduced vision due to age-related macular degeneration (AMD), cataract or glaucoma is the most common cause for CBS. Aim of this randomized controlled study was to assess whether additional treatment by a psychiatrist is beneficial for patients with CBS.

Methods and Analysis Patients with visual acuity of 0.5 LogMAR or worse in the better eye were screened. Instruments used were an interview asking about details of the $\mathrm{VH}$, a mental test and a questionnaire on quality of life. Patients with CBS were randomised into two groups: in group 1 , a patient-doctor consultation was performed by an ophthalmologist, and in group 2 a consultation and, if needed, additional medical assessment and treatment was given by a psychiatrist.

Results 4900 patients were screened. 390 patients met the inclusion criteria and among these a CBS prevalence of 34 patients (8.7\%) was found. The female-to-male ratio was $4: 1$ and the average age was $79.3 \pm 9.7$ years. Four different types of $\mathrm{VH}$ were observed: $41 \%$ humans $(n=14)$, $32 \%$ geometrical shapes/patterns ( $n=11), 15 \%$ plants $(n=5)$ and $12 \%$ animals $(n=4)$. The change in quality of life in patients with CBS was not significantly different in both groups ( $p=0.727$, ophthalmologist: $n=18$, psychiatrist: $\mathrm{n}=16)$.

Conclusion It is essential for medical staff involved with patients suffering from severe vision loss to be aware of CBS. This will help to better identify and interpret symptoms and could also lead to a more adequate treatment for affected patients.

Discussion It is essential for medical staff involved with patients suffering from severe vision loss to be aware of CBS. This will help to better identify and interpret symptoms and could also lead to a more adequate treatment for affected patients.

\section{INTRODUCTION}

Charles Bonnet, a Swiss philosopher, biologist and natural scientist, reported in 1760 the case of his grandfather, who had visual hallucinations (VHs). ${ }^{1}$ The patient was 89 years old, mentally and physically fit, suffering from bilateral cataracts and had VH describing people, birds or houses. The patient was

\section{Key messages}

What is already known about this subject?

- Patients with severe loss of vision (eg, due to agerelated macular degeneration, cataract, glaucoma) may suffer from visual hallucination (VH).

- VHs are often associated with mental illness and patients are afraid to tell medical staff about it.

\section{What are the new findings?}

- This is the first randomised controlled study which shows the quality of life for patients with Charles Bonnet syndrome (CBS) after a discussion with a psychiatrist or with an ophthalmologist.

- This paper provides all known diagnostic, inclusion and exclusion criteria which can be found in current literature.

- A relative high prevalence of CBS could have been found in this Austrian hospital.

How might these results change the focus of research or clinical practice?

- Increased awareness of CBS is necessary for medical staff and patients with vision loss. This will make it easier to identify and interpret symptoms correctly and also leads to adequate information and therapy for affected patients.

aware of the fact that these hallucinations were unreal. ${ }^{2-6}$

Georges des Morsier gave the name 'Charles Bonnet syndrome' (CBS) to VH, which occur in elderly, mentally fit patients. Much later, different authors suggested that $\mathrm{VH}$ in patients with CBS occur due to vision loss caused by ophthalmological diseases, such as age-related macular degeneration (AMD), other retinal diseases, cataract or glaucoma. ${ }^{457}$

Literature about CBS shows a large scale of diagnostic, inclusion and exclusion criteria. There is no commonly applied definition about CBS but most authors agree that patients have eye pathologies but no psychopathological disease (eg, dementia, psychosis or other neurological disease), have full insight that $\mathrm{VH}$ are unreal and $\mathrm{VH}$ are complex (eg, objects, faces, animals, plants 
or figures), repetitive and disappear when the eyes are closed, and there are no hallucinations affecting other sensory modalities. ${ }^{5-13}$

The current literature states that there are many different hypotheses about pathophysiology of CBS. VH may result from disorders in the visual cortex, visual perceptual disorders, overactivity in cortical areas or ageing. ${ }^{4131519}$

Patients fear being believed to be mentally ill, so they do not tell medical staff or even their relatives about their symptoms. ${ }^{21}$

Due to a lack of randomised controlled trials (RCTs), no evidence-based treatment for patients with CBS is available. It is presumed that VH would disappear with a better vision (eg, cataract surgery). Cox and Ffytche showed in 2014 that about one-third of patients with CBS are distressed from their $\mathrm{VH}^{21}$ Better information and awareness and an informative medical consultation may have a significant impact treating patients with CBS.

This study is a RCT of patients with CBS, using concrete diagnostic criteria. The intention of the authors was to assess the potential beneficial effect of an additional psychiatric evaluation (compared with a consultation between patient and ophthalmologist) for patients suffering from CBS.

\section{PATIENTS AND PUBLIC INVOLVEMENT}

Informed consent to participate in the trial was obtained from all patients prior to enrolment. Once this study is published, patients will be informed with an information sheet. Patients can choose if they wish to be informed about the study outcome or not, and how they want to receive the results (eg, by telephone or email).

Diagnostic and inclusion and exclusion criteria were defined using the current literature:

All patients participating in the trial had to have a visual acuity of $0.5 \operatorname{LogMAR}{ }^{7}$ or worse in the better eye and a minimum age of 55 years. To give clear guidance for our data, different tools (guided interview, quality-oflife scale, minimental-state examination) for diagnosing CBS were used.

Using the modified Telephone Interview for Cognitive State (TICS-m) it was ensured that patients with CBS:

- Have no mental pathologies such as dementia, psychosis or any other neurological diseases. ${ }^{6-11}$

- Have a normal cognitive state. ${ }^{810}$

- Are not able to control the $\mathrm{VH}^{8}$

- Know that the VH are not real. ${ }^{5710-1222}$

- Are usually older. ${ }^{910}$

- Have significantly reduced visual acuity due to bilateral ocular pathology. ${ }^{9} 10$

Additionally there are no:

- Auditory or olfactory hallucinations. ${ }^{57811} 22$

- Other abnormalities such as delusions. ${ }^{57811} 1222$

The North East Visual Hallucination Interview (NEVHI) gathered data regarding the description of VH associated with CBS:

- Disappear when the eyes are closed. ${ }^{8}$
- Are repetitive. ${ }^{8}$

- Are complex (eg, objects, geometrical patterns, faces, shapes, figures, scenes, animals or plants). ${ }^{4710-12152324}$

Furthermore, we excluded patients who were on dopamine agonist medication, patients with a temporal lobe epilepsy, a moderate to severe Alzheimer's dementia, a present chronic alcohol/drug abuse or a bad cognitive state.

Patients with a visual acuity of $0.5 \log$ MAR or worse in both eyes were screened at the Department of Ophthalmology in Hanusch Hospital, Vienna asking them a standardised question: ${ }^{22} 25-28$

'Sometimes people who have an eye disease with bad vision see images or hallucinations that are actually not real or see things that other people do not see. This is a known condition called CBS. It happens to people who are of sound mind and have no mental or psychiatric illness. Have you ever experienced any VH?

If patients responded in the affirmative, the patient was asked whether he/she would like to participate in the trial.

Patients were asked to describe and draw the VHs. Furthermore, their medical history was taken in detail. In order to check the exclusion criteria, standardised tests, such as the NEVHI, ${ }^{29}$ the Satisfaction with Life Scale (SWLS) ${ }^{30}$ and the TICS-m, ${ }^{31}$ were used to assess VH, the quality of life and possibly dementia.

All patients were allocated into two groups using randomisation by minimisation with the online randomisation tool 'QMinim Online Minimisation'.

Variables for randomisation were: visual acuity: worse than 1.0 LogMAR or 0.50-1.0 LogMar, and if patients had significant problems due to the $\mathrm{VH}$, or if the $\mathrm{VH}$ were not causing a reduction in quality of life.

The control group had a face-to-face interview with their ophthalmologist explaining the nature of CBS. Patients in the study group received a detailed clinical exploration, and if deemed useful, a medical therapy by a psychiatrist.

After 3 months of the first visit, patients were interviewed again with the NEVHI and the SWLS to assess, if there was a change concerning their CBS symptoms and in quality of life.

\section{RESULTS}

4900 patients were screened, of which 390 patients with a visual acuity of less than $0.5 \operatorname{LogMAR}$ in the better eye were found. Simple VHs such as floaters were reported in $18.5 \%(n=72)$. In total, $11.8 \%(n=46)$ had complex VHs such as seeing people or faces $(n=14)$, geometrical patterns or figures $(n=11)$, plants $(n=5)$ and animals $(n=4)$. Twelve patients with complex VHs were excluded due to following reasons: four patients had a reduced state of cognition (less than 33 points at the TICS-m), three patients had a visual acuity of better than 0.5 LogMAR (on testing for trial entry), two patients had a moderate to severe Alzheimer's dementia, and one patient had temporal lobe epilepsy, medication with dopamine 
Table 1 The demographic data of all patients with CBS $(n=34)$ compared with the entire population $(n=390)$

\begin{tabular}{|c|c|c|}
\hline & CBS $(n=34)$ & $\begin{array}{l}\text { Screened } \\
\text { population } \\
(\mathrm{n}=390)\end{array}$ \\
\hline Characteristics of & Number (\%) & Number (\%) \\
\hline \multicolumn{3}{|l|}{ Sex } \\
\hline Female & $28(82)$ & $261(67)$ \\
\hline Male & $6(18)$ & $129(33)$ \\
\hline \multicolumn{3}{|l|}{ Visual acuity * } \\
\hline $0.5-0.71$ & $15(44)$ & $51(13)$ \\
\hline $0.7-1.0$ & $14(41)$ & $163(42)$ \\
\hline$<1.0$ & $5(15)$ & $176(45)$ \\
\hline \multicolumn{3}{|l|}{ Ophthalmic diagnosis } \\
\hline Age-related macular degeneration & $23(67)$ & $238(61)$ \\
\hline DME & $5(15)$ & $62(16)$ \\
\hline Cataract & $2(6)$ & $55(14)$ \\
\hline Other retinal diseases & $2(6)$ & $15(4)$ \\
\hline Occlusion & $1(3)$ & $8(2)$ \\
\hline \multirow[t]{2}{*}{ CME } & $1(3)$ & $8(2)$ \\
\hline & & $4(1)$ \\
\hline
\end{tabular}

\section{Living conditions}

\begin{tabular}{lr} 
Alone & $15(44)$ \\
With family or other persons & $14(41)$ \\
In nursing home & $5(15)$ \\
Visual hallucinations & \\
People, faces & $14(41)$ \\
Geometrical patterns, figures & $11(32)$ \\
Plants & $5(15)$ \\
Animals & $4(12)$ \\
\hline
\end{tabular}

*LogMar.

CBS, Charles Bonnet syndrome; CME, cystoid macular edema; DME, diabetic macular edema.

agonists or was not willing to participate. Therefore, the prevalence of the CBS patients with a visual acuity of less than 0.5 LogMAR at our department was $8.7 \%(n=34)$.

Table 1 shows demographic data of all included patients with CBS $(n=34)$ compared with the entire population $(n=390)$. Of the 34 patients with CBS, 28 were female and 6 were male, respectively. Mean age was 79.3 years with a

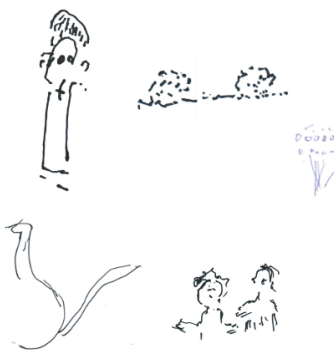

Figure 1 Examples of visual hallucinations drawn by different patients.
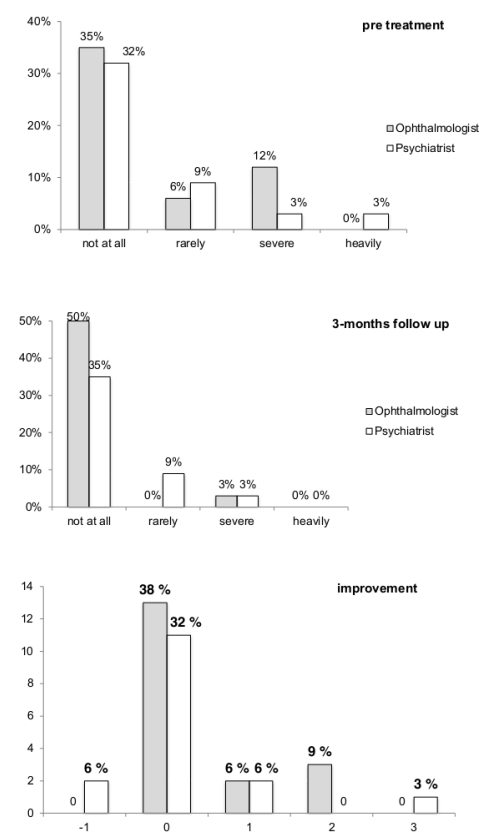

Figure 2 Psychological strain before and after treatment.

range from 55 to 97 years and an SD of 9.7 years. Figure 1 shows examples of VHs drawn by different patients.

After randomisation by minimisation, 18 patients had a face-to-face consultation with an ophthalmologist (control group) and 16 patients received further exploration and possible medical treatment by a psychiatrist (study group). In six cases in the study group medication was offered to the patients: three declined, two received Sertraline and one patient received Trittico (both selective serotonin reuptake inhibitors).

Figure 2 shows the psychological strain before and after treatment. There was no statistically significant difference found between the control and the study group $(\mathrm{p}=0.727)$.

\section{DISCUSSION}

CBS is defined by the occurrence of $\mathrm{VH}$ in the absence of any mental disorder. Elderly patients with reduced visual acuity due to ophthalmic disease are most affected. Conditions often associated with the syndrome are AMD, cataract and glaucoma. Existing data on the syndrome's prevalence in Europe reveals diverse results.

The aim of this study was to evaluate, if additional treatment by a psychiatrist is beneficial and also to assess the prevalence of CBS in patients with low visual acuity.

Most of our patients with CBS were relieved to learn that they are not mentally ill and there is a known syndrome for their symptoms. However, to date, there is no approved medical treatment for patients suffering from CBS. Our attempt to compare a discussion with an ophthalmologist and a psychiatrist showed that almost all patients felt more worried about losing their eyesight because of their eye disease rather than about having VH.

The prevalence of the CBS at our department was relatively low in comparison to other studies. In Europe, Teunisse $e t a l,{ }^{7}$ Ffytche and Howard ${ }^{14} /$ Cox and Ffytche ${ }^{21}$, 
Santhouse $e t a l,{ }^{20}$ Cohen $e t a l,{ }^{27}$ Lannon $e t a l,{ }^{32}$ Abbott $e t$ $a l^{23}$ or Jackson et $a l^{25}$ showed a higher prevalence of CBS. These differences could be due to rather vague diagnostic, inclusion and exclusion criteria. Therefore, it is not surprising that the estimated number of not reported cases of CBS is high. In this study, we excluded patients with psychiatric/neurological pathologies (eg, dementia or Parkinson's disease) and we differentiated between simple and complex VHs. The prevalence of CBS would be much higher if these exact criteria had not been considered.

In the literature, different criteria for CBS are mentioned, but currently there are no standardised diagnostic criteria for CBS. Visual acuity as an influencing factor for development of CBS is often discussed. With regard to the study of Teunisse et $a l^{7}$ we also chose the limit of visual acuity for patients to be screened at $0.5 \operatorname{LogMAR}$. Due to our results of patients with CBS compared with the entire population, we assume that patients with CBS may sometimes have better visual acuity, potentially $0.5-0.70 \operatorname{LogMAR}$. In a future trial it could be worth considering using different groups of visual acuity and a longer period of observation to find out if a loss of visual acuity causes $\mathrm{VH}$ or in reverse, an increase of visual acuity can stop $\mathrm{VH}$, such as in cataract patients after surgery.

Additionally, we found that our demographic data, such as sex or age distribution, were similar to other studies.

Due to a lack of RCTs, there is no evidence-based treatment for patients with CBS who suffer from VH. In this study, clearly defined criteria for diagnosing a CBS were used and patients were randomised in two groups to find out whether a consultation with a psychiatrist is a potential benefit for patients with CBS.

With the limitation of small sample size in the study and control group, we show that competent advice and explanation to patients with CBS is essential. We were not able to show an added benefit from psychiatric evaluation.

\section{CONCLUSION}

Summing up, patients had a relevant benefit from learning about CBS and they were relieved that no mental illness is involved. Furthermore, prevalence of CBS strongly depends on the inclusion and exclusion criteria. Although the face-to-face consultation with an expert is of great importance, an additional psychiatric therapy showed no benefit for patients involved in our study group. However, in several cases the underlying cause of VH is not CBS and these patients may benefit from an interdisciplinary working with psychiatry and neurology. It is essential for people involved with patients suffering from severe vision loss to learn more about CBS. This will make it easier to identify and interpret symptoms correctly and might also lead to a more adequate information and therapy for affected patients. For further studies precise and standardised diagnostic criteria should be defined.
Contributors BD was responsible for the study conception and design, data acquisition, analysis, interpretation and writing of the manuscript. MK and LS were concerned with data acquisition and interpretation. NH and OF had substantial contribution in the study conception and design. All authors revised and approved the final version of the manuscript.

Funding The authors have not declared a specific grant for this research from any funding agency in the public, commercial or not-for-profit sectors.

Competing interests None declared.

Patient and public involvement Patients and/or the public were not involved in the design, or conduct, or reporting, or dissemination plans of this research.

Patient consent for publication Not required.

Ethics approval All the research and measurements followed the tenets of declaration of Helsinki and the local ethics committee approved the study.

Provenance and peer review Not commissioned; externally peer reviewed.

Data availability statement Data are available upon request.

Open access This is an open access article distributed in accordance with the Creative Commons Attribution Non Commercial (CC BY-NC 4.0) license, which permits others to distribute, remix, adapt, build upon this work non-commercially, and license their derivative works on different terms, provided the original work is properly cited, appropriate credit is given, any changes made indicated, and the use is non-commercial. See: http://creativecommons.org/licenses/by-nc/4.0/.

ORCID iD

Birgit Doeller http://orcid.org/0000-0001-6133-1469

\section{REFERENCES}

1 Olbrich HM, Engelmeier MP, Pauleikhoff D, et al. Visual hallucinations in ophthalmology. Graefes Arch Clin Exp Ophthalmol 1987;225:217-20.

2 Lerario A, Ciammola A, Poletti B, et al. Charles Bonnet syndrome: two case reports and review of the literature. J Neurol 2013;260:1180-6.

3 Eperjesi F, Akbarali N. Rehabilitation in Charles Bonnet syndrome: a review of treatment options. Clin Exp Optom 2004;87:3:149-52.

4 O'Farrell L, Lewis S, McKenzie A, et al. Charles Bonnet syndrome: a review of the literature. J Vis Impair Blind 2010;104:261-74.

5 Jan T, Del Castillo J. Visual hallucinations: Charles Bonnet syndrome. West J Emerg Med 2012;13:544-7.

6 Paradowski B, Kowalczyk E, Chojdak-Łukasiewicz J, et al. Three cases with visual hallucinations following combined ocular and occipital damage. Case Rep Med 2013;2013:1-5.

7 Teunisse RJ, Cruysberg JR, Verbeek A, et al. The Charles Bonnet syndrome: a large prospective study in the Netherlands. A study of the prevalence of the Charles Bonnet syndrome and associated factors in 500 patients attending the University department of ophthalmology at Nijmegen. Br J Psychiatry 1995;166:254-7.

8 Schultz G, Melzack R. The Charles Bonnet Syndrome: 'Phantom Visual Images'. Perception 1991;20:809-25.

9 Menon GJ, Rahman I, Menon SJ, et al. Complex visual hallucinations in the visually impaired: the Charles Bonnet syndrome. Surv Ophthalmol 2003;48:58-72.

10 Teunisse RJ, Cruysberg JR, Hoefnagels WH, et al. Visual hallucinations in psychologically normal people: Charles Bonnet's syndrome. Lancet 1996;347:794-7.

11 Vale TC, Fernandes LC, Caramelli P. Charles Bonnet syndrome: characteristics of its visual hallucinations and differential diagnosis. Arq Neuropsiquiatr 2014;72:333-6.

12 Gold K, Rabins PV. Isolated visual hallucinations and the Charles Bonnet syndrome: a review of the literature and presentation of six cases. Compr Psychiatry 1989;30:90-8.

13 Pang L. Hallucinations experienced by visually impaired: Charles Bonnet syndrome. Optom Vis Sci 2016;93:1466-78.

14 ffytche DH, Howard RJ. The perceptual consequences of visual loss: 'positive' pathologies of vision. Brain 1999;122 (Pt 7:1247-60.

15 Collerton D, Perry E, McKeith I. Why people see things that are not there: a novel perception and attention deficit model for recurrent complex visual hallucinations. Behav Brain Sci 2005;28:737-57.

16 Höflich A, Baldinger P, Lanzenberger R. Steckbrief seltener Krankheiten: Das Charles Bonnet-Syndrom. J Neurol Neurochir Psychiatr 2012;13:187-9.

17 Elbers N, Geraerts E, van Heerden J. Hallucinating consistency. Theory Psychol 2007;17:587-602. 
18 Siatkowski RM, Zimmer B, Rosenberg PR. The Charles Bonnet syndrome. visual perceptive dysfunction in sensory deprivation. $J$ Clin Neuroophthalmol 1990;10:215-8.

19 Ffytche DH. Visual hallucinatory syndromes: past, present, and future. Dialogues Clin Neurosci 2007;9:173-89.

20 Santhouse AM, Howard RJ, ffytche DH. Visual hallucinatory syndromes and the anatomy of the visual brain. Brain 2000;123:2055-64.

21 Cox TM, ffytche DH. Negative outcome Charles Bonnet syndrome. Br J Ophthalmol 2014;98:1236-9.

22 Tan CSH, Lim VSY, Ho DYM, et al. Charles Bonnet syndrome in Asian patients in a tertiary ophthalmic centre. $\mathrm{Br} J$ Ophthalmol 2004;88:1325-9.

23 Abbott EJ, Connor GB, Artes PH, et al. Visual loss and visual hallucinations in patients with age-related macular degeneration (Charles Bonnet syndrome). Invest Ophthalmol Vis Sci 2007;48:1416-23.

24 Teeple RC, Caplan JP, Stern TA. Visual hallucinations: differential diagnosis and treatment. Prim Care Companion J Clin Psychiatry 2009;11:26-32.

25 Jackson ML, Bassett K, Nirmalan PV, et al. Contrast sensitivity and visual hallucinations in patients referred to a low vision rehabilitation clinic. Br J Ophthalmol 2007;91:296-8.
26 Zhang H, Liu Z-L, Sun P, et al. Incidence of Charles Bonnet syndrome after intravitreal bevacizumab injection in neovascular age-related macular degeneration. Acta Ophthalmol 2012;90:e647-8.

27 Cohen SY, Bulik A, Tadayoni R, et al. Visual hallucinations and Charles Bonnet syndrome after photodynamic therapy for age related macular degeneration. Br J Ophthalmol 2003;87:977-9.

28 Pliskin NH, Kiolbasa TA, Towle VL, et al. Charles Bonnet syndrome: an early marker for dementia? J Am Geriatr Soc 1996;44:1055-61.

29 Mosimann UP, Collerton D, Dudley R, et al. A semi-structured interview to assess visual hallucinations in older people. Int J Geriatr Psychiatry 2008;23:712-8.

30 Glaesmer H, Grande G, Braehler E. The German version of the satisfaction with life scale - psychometric properties and population based norms. Eur J Psychol Assess 2011;27:127-32.

31 Matrisch M, Trampisch U, Klaaßen-Mielke R. Demenzscreening per telefon: eine reliabilitäts- und evaluationsstudie zum telefoninterviews für den kognitiven status (tics) in seiner modifizierten deutschen Fassung. $Z$ Gerontol Geriatr 2012;45:218-23.

32 Lannon SP, Stevenson MR, White ST, et al. Visual hallucinations in patients with age-related macular degeneration (AMD). Vis Impair Res 2006;8:9-16. 